\title{
SECONDARY PULMONARY HODGKIN LYMPHOMA: A CASE REPORT
}

\author{
Ramesh Babu Chidambaram¹, Geetha Devadas², Sudha Venkatesh ${ }^{3}$
}

${ }_{1}^{1}$ Post Graduate, Department of Pathology, Madras Medical College, Chennai.

2 Professor, Department of Pathology, Madras Medical College, Chennai.

2Professor, Department of Pathology, Madras Medical College, Chennai.

\section{ABSTRACT}

Hodgkin Lymphoma most frequently involves the lymph node. Extranodal involvement is very rare. Involvement of lung is relatively rare in Hodgkin Lymphoma and accounts for 5.9-11.6\% (Ref. 1). Hence, we report a case of Hodgkin Lymphoma with pulmonary relapse.

\section{KEYWORDS}

Hodgkin Lymphoma, Secondary Pulmonary Hodgkin Lymphoma.

HOW TO CITE THIS ARTICLE: Chidambaram RB, Devadas G, Venkatesh S. Secondary pulmonary Hodgkin lymphoma: a case report. J. Evolution Med. Dent. Sci. 2016;5(62):4402-4404, DOI: 10.14260/jemds/2016/1006

\section{INTRODUCTION}

Hodgkin Lymphoma is most commonly seen in the lung as secondary involvement. It affects young adults with median age of 42 years with slight female predisposition. Incidence of lung involvement at initial presentation is $12 \%$ in Hodgkin's and $4 \%$ in Non-Hodgkin's Lymphoma. The diagnosis of Hodgkin Lymphoma in lung is based on the recognition of diagnostic Reed-Sternberg cells with reactive cellular infiltrate in the background. Nodular sclerosis and mixed cellularity are the common histological findings. Cytological identification of Reed-Sternberg cells have been of considerable clinical assistance in determining the pulmonary lesion (Ref. 2).

\section{CASE PRESENTATION}

A 33-year-old male admitted with history of cough, with sputum for 3 months, swelling in the right cervical region, right side of the chest wall and ulcer in the right axilla. In 2011, this patient presented with swelling in the cervical region. FNAC was done and reported as granulomatous lymphadenitis. He was started on ATT. There was no response to the treatment, excision biopsy was done and reported as Hodgkin Lymphoma (Nodular Sclerosis type). He was started on chemotherapy and defaulted treatment for 2 years.

Present Chest X-ray illustrated right upper zone consolidation. CT chest showed homogeneously enhancing soft tissue lesion measuring about $9.6 * 6.4 * 4.5 \mathrm{~cm}$ involving right axilla and chest wall. Adjoining rib appears normal, $3.6 * 3.5 \mathrm{~cm}$ heterogeneously enhancing mass lesion with compression of right upper lobe bronchus with consolidation with air bronchogram and cavitation noted in right upper lobe. Evidence of multiple nodules/mass lesion of varying size noted in bilateral lung fields, hypodense lymph node in right paratracheal, superior mediastinum. Sputum AFB was negative. Patient was subjected to transbronchoscopy, bronchial wash and biopsy was taken.

Financial or Other, Competing Interest: None.

Submission 24-06-2016, Peer Review 22-07-2016,

Acceptance 27-07-2016, Published 04-08-2016.

Corresponding Author:

Dr. Ramesh Babu Chidambaram,

\#53/23, $1^{\text {st }}$ Floor

Patchaippan Street

Mount Road,

Chennai- 600002

E-mail: drraja1981@gmail.com

DOI: $10.14260 /$ jemds/2016/1006
Smears from the bronchial wash showed polymorphous population of lymphocytes, neutrophils, mononuclear giant cells showing prominent nucleoli, occasional binucleate cells and scattered endobronchial cells in haemorrhagic background. Impression given as features suggestive of Hodgkin Lymphoma (Figure. 1 and 2).

FNAC from the cervical node appeared moderately cellular showing polymorphous infiltration of mature lymphocytes, eosinophils, mononuclear giant cells with prominent nucleoli, occasional bi-nucleate Reed Sternberg cells, epithelioid granuloma in a fibrinous background. Impression given as suggestive of Hodgkin Lymphoma (Figure 3).

Sections from the transbronchial lung biopsy showed portion of lung parenchyma and adjoining fibro-collagenous tissue infiltrated by lymphocytes, plasma cells, eosinophils, mononuclear cells and occasional bi-nucleate large cells showing prominent nucleoli. Impression given as features indicative of Hodgkin Lymphoma. IHC was suggested for confirmation (Figure 4 and 5).

IHC was done. CD 30 showed positive in all mononuclear cells (Figure 6) and CD 15 showed focal positivity in the mononuclear cells (Figure 7). IHC features confirmed the diagnosis of Hodgkin Lymphoma.

On subsequent follow-up of the patient it was revealed that alternate complete chemotherapeutic regimen was advocated; there was complete resolution of the nodes and pulmonary lesions.

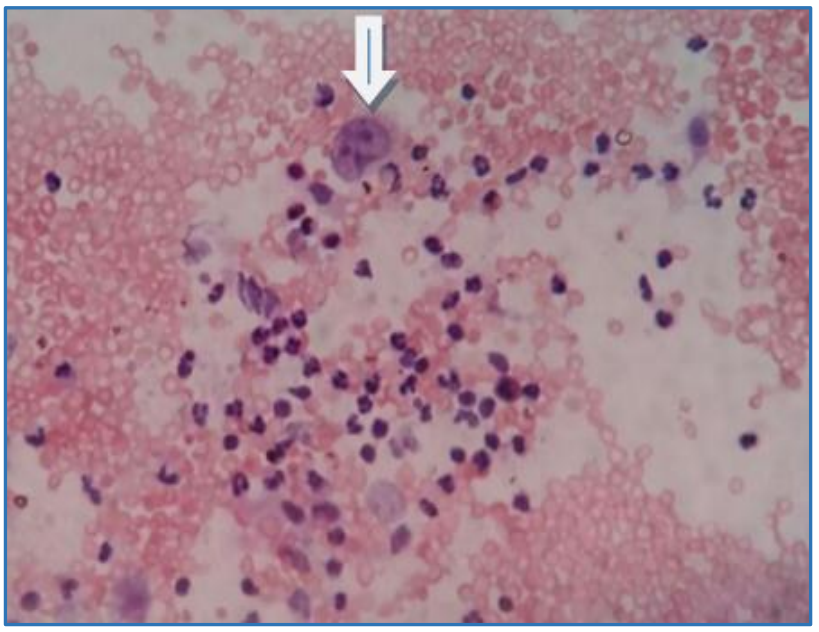

Fig. 1 


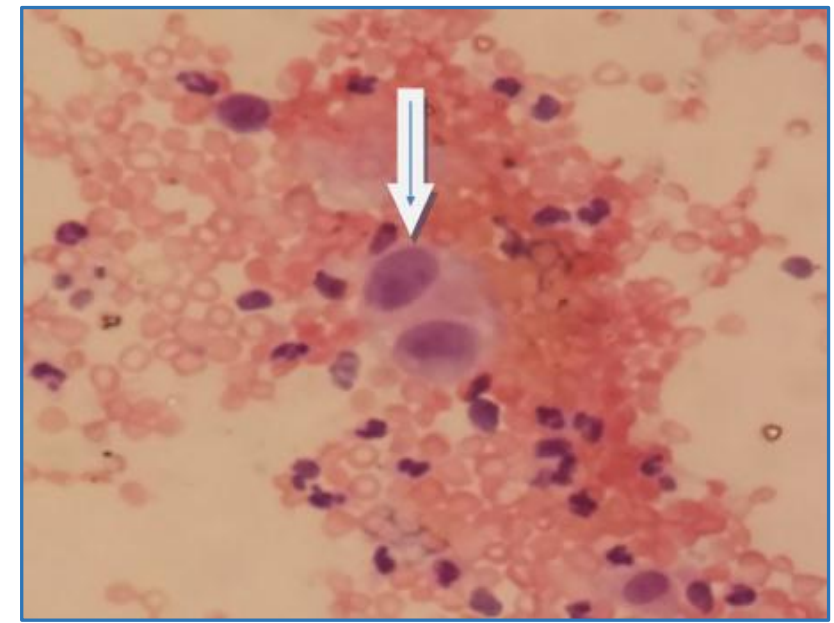

Fig. 1 \& 2: Images showing Reed-Sternberg Cell (Arrow), Few endobronchial Cells and Inflammatory Cells in Bronchial wash Cytology (Pap Stain, 10x and 40x Magnification)

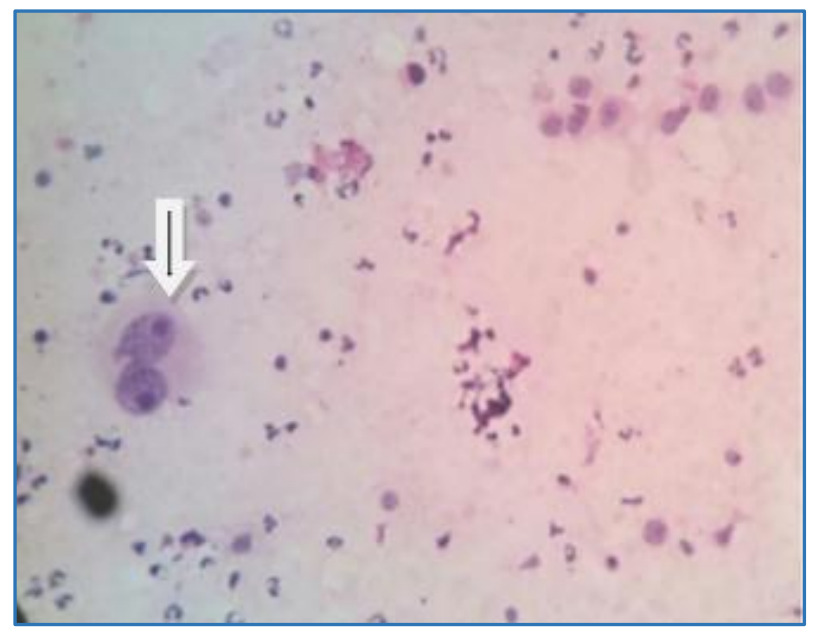

Fig. 3: Image showing Reed-Sternberg Cell (Arrow) in FNAC of Cervical Node (Pap Stain, 40X Magnification)

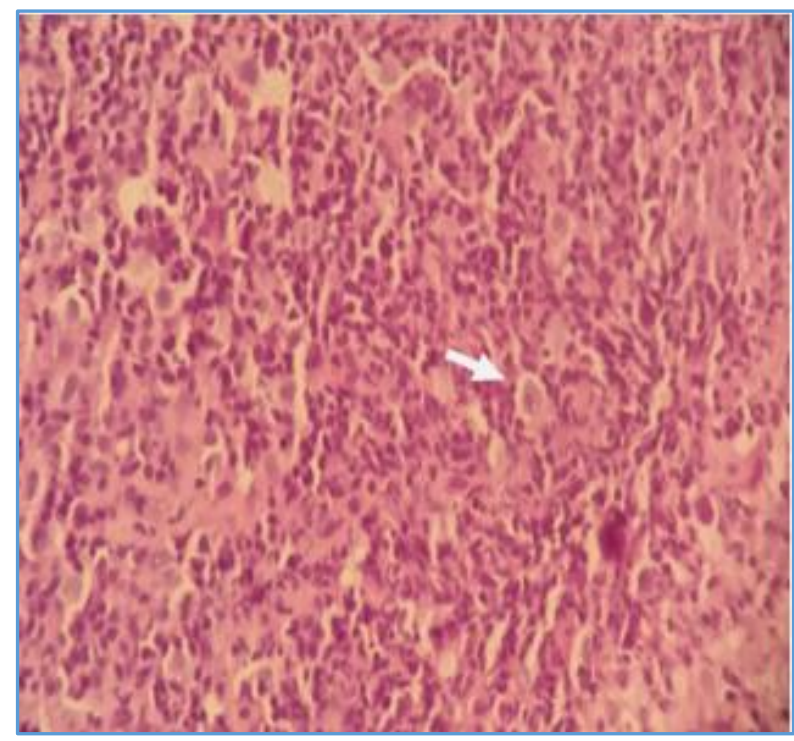

Fig. 4

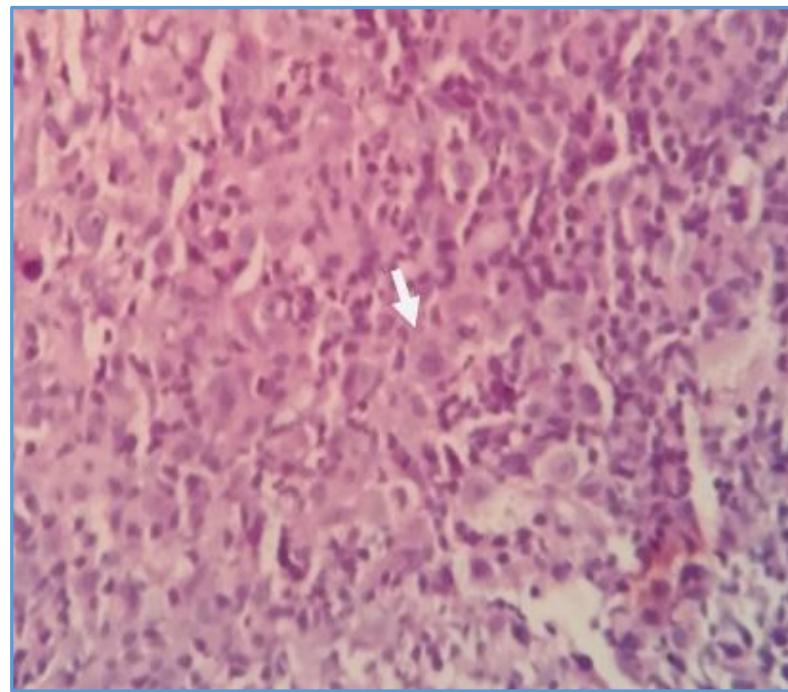

Fig. 4 \& 5: Images showing Mononuclear Cells (Arrow) in Transbronchial Biopsy (H\&E Stain, 40X Magnification)

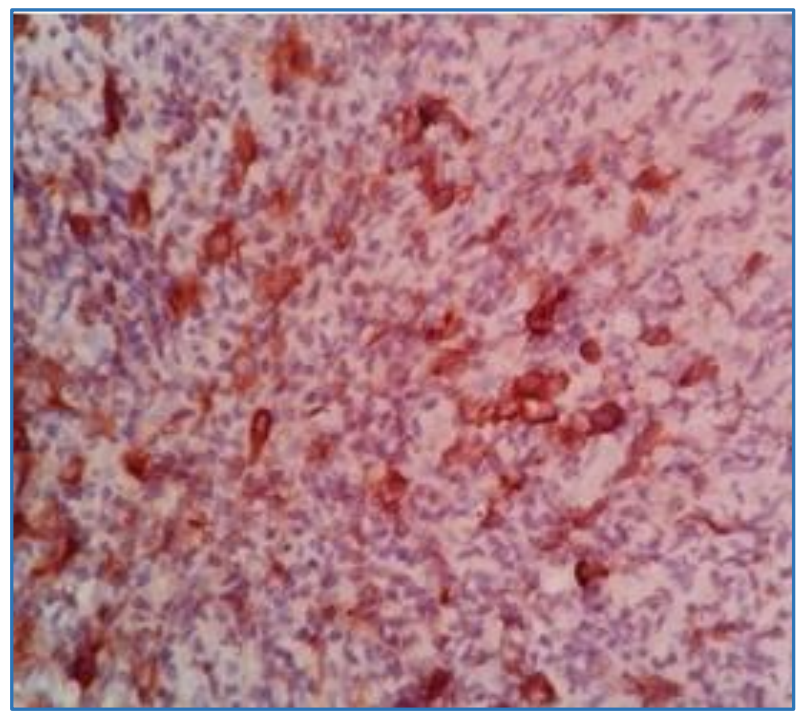

Fig. 6: CD30 Positivity in All Mononuclear Cells

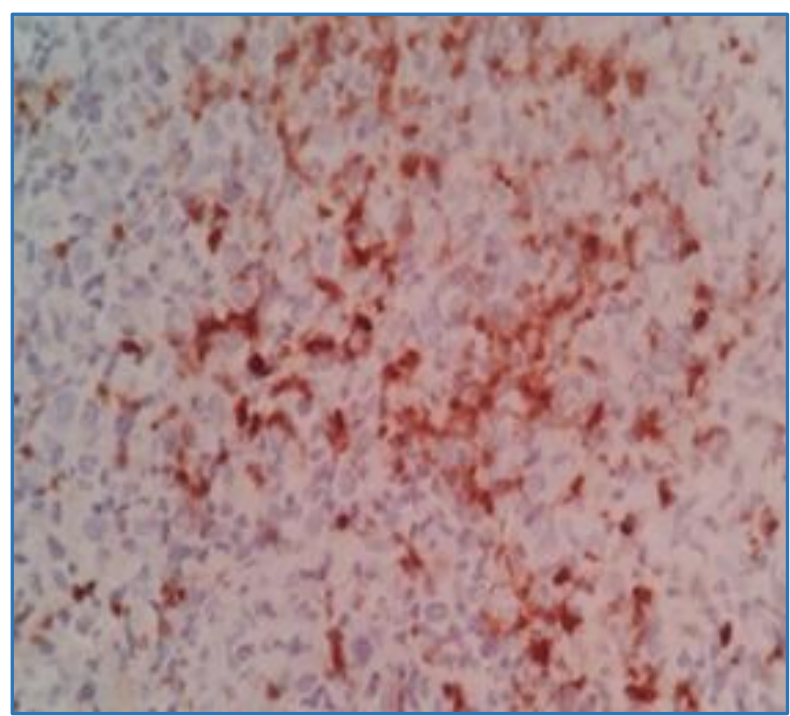

Fig. 7: CD15 - Focal Positivity in Mononuclear Cells 


\section{DISCUSSION}

Hodgkin Lymphoma most frequently involves the lymph node; extranodal involvement is very rare. Lung is the commonest secondary involvement of Hodgkin Lymphoma. Pulmonary involvement in lymphoma may be classified under 3 broad categories:

1) Primary Hodgkin Lymphoma, 2) Primary Non-Hodgkin's Lymphoma, 3) Lymphoma in association with existing or previously treated nodal disease.

Lung constitutes about $40.9 \%$ and the median age is 28 years. Male-to-female ratio is 2.1:1 (Ref. 3). Incidence of lung involvement in initial presentation is $12 \%$ in Hodgkin and $4 \%$ in Non-Hodgkin Lymphoma. Secondary pulmonary involvement occurring in course of Hodgkin Lymphoma occurs in $12-40 \%$ of the patients (Ref. 4).

In Hodgkin Lymphoma, pulmonary involvement is almost always associated with radiographically evident hilar and mediastinal lymphadenopathy.

Non-Hodgkin Lymphoma may involve the mediastinal nodes and lungs or may be limited to the lungs. Pulmonary involvement occurs in $30-40 \%$ of patients with Hodgkin Lymphoma at some stage, usually as secondary or recurrent disease. The incidence of pulmonary involvement in nonHodgkin Lymphoma is less than that of Hodgkin Lymphoma.

CT appearance is useful in establishing or suggesting the diagnosis of pulmonary relapse. Enlarged mediastinal nodes are not prerequisite, but had been present in all patients at some stage in the course of the disease (Ref. 5). CT Chest shows lung mass in case of primary pulmonary lymphoma and pleural, mediastinal and hilar lymphadenopathy in case of secondary pulmonary lymphoma (Ref. 6).

Patients with Hodgkin Lymphoma involving extranodal sites had relatively poor survival rate. The most common extranodal sites of involvement are liver and lung followed by bone. The diagnosis of Hodgkin Lymphoma is usually confirmed by demonstrating the appropriate immunophenotype CD30, CD15 positive and CD45 negative.

\section{CONCLUSION}

Although, Hodgkin Lymphoma with extranodal involvement is not common, it should be considered as unique form and a rare presentation of Hodgkin Lymphoma. Cytology and transbronchial biopsy should be carried out as early as possible to rule out secondary pulmonary involvement. Early detection of pulmonary lesions aids in planning effective or alternate chemotherapeutic strategies to achieve complete remission.

\section{REFERENCES}

1. Guermazi A, Brice P, Kerviler EE, et al. Extranodal Hodgkin's disease, spectrum of disease. Radiographics 2001;21(1):161-79.

2. Cimbaluk KD, Gattuso P. Reed sternberg cells in bronchial brushing from a patient with Hodgkin's lymphoma. Diagnostic Cytopathology 2006;34(12):850-1.

3. Zhi-Ming Li, Ying-Jie Zhu, Yi-Xla, et al. Clinical characteristics of the patients with Hodgkin lymphoma involving extranodal sites. Chinese journal of cancer 2012;31(7):342-7.

4. Yaoqian C, Jiecao, Haiyan Z, et al. Secondary Pulmonary Hodgkin's Lymphoma of lung. Chest world congress 2016;149(4):A333.

5. Cobby M, Whipp E, Bullimore J, et al. CT appearance of relapse of lymphoma in lung. Clinical Radiol 1990;41(4):232-8.

6. Niu X, Hu H, Gao J, et al. A clinical analysis of 40 cases of primary and secondary pulmonary lymphoma. ZhonghuaJie He He Hu Xi Za Zhi 2014;37(7):502-6. 